\title{
Parental chronic pain and internalizing symptoms in offspring: the role of adolescents' social competence - the HUNT study
}

This article was published in the following Dove Press journal: Journal of Pain Research

\author{
Jannike Kaasbø|I',2 \\ Stian Lydersen ${ }^{2}$ \\ Ingunn Ranøyen ${ }^{2,3}$ \\ Wendy Nilsen ${ }^{4}$ \\ Marit S Indredavik ${ }^{2,3}$ \\ 'Department of Health Research, \\ SINTEF, Trondheim, Norway; \\ ${ }^{2}$ Department of Mental Health, Faculty \\ of Medicine and Health Sciences, \\ Regional Centre for Child and Youth \\ Mental Health and Child Welfare \\ (RKBU Central Norway), Norwegian \\ University of Science and Technology \\ (NTNU), Trondheim, Norway; \\ ${ }^{3}$ Department of Children and Youth, \\ Division of Mental Health Care, St. \\ Olavs Hospital, Trondheim University \\ Hospital, Trondheim, Norway; ${ }^{4}$ The \\ Work Research Institute, OsloMet - \\ Oslo Metropolitan University, Oslo, \\ Norway
}

Background: A growing body of research suggests that the children of parents with chronic pain are at risk for internalizing symptoms. The mechanisms of such associations have not been as thoroughly examined. The aim of the present study was to investigate whether adolescents' social competence mediates the association between parental chronic pain and offspring internalizing symptoms as well as whether these associations are moderated by adolescent gender.

Methods: The current study was based on cross-sectional data from the Nord-Trøndelag Health Study (HUNT 3), a Norwegian population-based health survey conducted in 2006-2008. The present sample comprised adolescents who had both parents participating $(n=9,681)$. Structural equation modeling was used for the data analysis.

Results: Our results indicated that the association between concurrent maternal and paternal chronic pain and offspring's symptoms of anxiety and depression was partly mediated by low social competence for girls $(\mathrm{b}(\mathrm{SE})=0.060$ [0.030], $P=0.043$ ) but not for boys $(\mathrm{b}(\mathrm{SE})=-0.059$ $[0.040], P=0.146)$. This suggests that these associations are moderated by offspring gender.

Conclusion: The study extends the existing literature on the possible pathways between parental chronic pain and internalizing symptoms in the offspring. Identifying protective factors in the pathways between parental chronic pain and mental distress in children could guide measures that promote the wellbeing of the child and family of chronic pain sufferers.

Keywords: chronic pain, adolescents, social competence, anxiety, depression, sex differences

\section{Introduction}

In Europe, $\sim 20 \%$ of adults live with moderate to severe chronic pain ${ }^{1}$ and a large proportion of these are parents. Research findings suggest there is substantial impact of chronic pain on the general well-being of the family. ${ }^{2-4}$ Parental physical illness affects the children's psychological adjustment, especially with internalizing problems. ${ }^{5-7}$ Recent literature reviews emphasized the need to uncover variables that mediate or moderate the association between parental chronic pain and children's outcomes. ${ }^{8,9}$ Identifying protective factors in the pathways between parental chronic pain and mental distress in children could guide measures to promote the well-being of the child and family. ${ }^{9,10}$

Social competence designates how well one is getting along with other people and forming close relationships, ${ }^{11}$ and it is a fundamental aspect of children's adjustment. ${ }^{12}$ Social competence is a term that includes social skills as well as other behavioral, cognitive, and emotional traits necessary to develop and maintain adequate social relationships. The social skills construct contains different dimensions, such as perspective taking (cognitive), empathy (emotional), and cooperation and self-control
Correspondence: Jannike Kaasbøll Department of Health Research, SINTEF, Klæbuveien 153, 7049 Trondheim, Norway

Tel +4795191984

Email jannike.kaasboll@sintef.no 
(behavioral). ${ }^{13}$ However, in the literature, the terms social competence and social skills are often used interchangeably. ${ }^{14}$ Thus, in this article, we refer to studies focusing on both social competence and social skills. In previous studies, adolescent boys were found to have higher levels of social competence than girls. ${ }^{15-17}$ Cross-sectional studies focusing on the connections between children's competence and their behavioral adjustments have reported an inverse relationship between social competence and internalizing symptoms. ${ }^{16-18}$ Furthermore, long-term associations between childhood social competence and adult mental health have been reported. ${ }^{19-21}$ According to recent studies on the developmental cascades and trajectories of social competence and internalizing behavioral adjustments, ${ }^{11,22-25}$ social competence antecedes the behavioral adjustment, including internalizing problems such as anxiety and depression.

Previous research suggests that the children of chronic pain patients may have social competence deficits. ${ }^{26-28}$ In a previous study, we found that concurrent maternal and paternal chronic pain was associated with reduced social competence in girls, whereas maternal chronic pain was associated with higher social competence in boys. ${ }^{29}$ Chronic pain is associated with social isolation and withdrawal ${ }^{2,30-32}$ as well as by the fact that chronic pain extends over time..$^{28,32,33}$ Parental chronic pain could substantially impact the familial and social environment. ${ }^{2,34,35}$ Social learning, such as parental modeling and reinforcement, constitutes one plausible mechanism for the transmission of risk from parents to offspring. ${ }^{36}$ Because family relationships are central for developing social competence in children, ${ }^{37-40}$ it is possible that parental chronic pain could influence levels of social competence in the offspring. Additionally, parental symptoms of anxiety and depression and confounding factors, such as socioeconomic status, increasing age, and organ-specific illness, should be taken into account because these factors are associated with both parental chronic pain and child outcomes. ${ }^{5,21,41-44}$ Because parental chronic pain is associated with internalizing symptoms in offspring, high levels of social competence could be a potential protective factor in the development of internalizing symptoms. Still, to the best of our knowledge, there are no studies investigating the potential links between parental chronic pain, adolescent offspring's social competence, and symptoms of anxiety and depression.

The overall aim of the present study was to explore the role of social competence in the associations between parental chronic pain and psychological symptoms in the offspring. First, we aimed to describe self-reported social competence in children whose mothers, fathers, both or neither parents had chronic pain. Next, we examined whether adolescents' social competence mediated the association between parental chronic pain and offspring's symptoms of anxiety and depression while adjusting for potential confounders. Finally, because adolescent boys were previously found to have higher levels of social competence than girls, we examined whether the offspring's sex moderated these relationships.

\section{Materials and methods Study design and procedures}

The current study uses data from a large population-based survey, The Nord-Trøndelag Health Study (HUNT 3), which is a survey of the entire adolescent and adult population in the county of Nord-Trøndelag, central Norway. Data were collected from 2006 to 2008 and all inhabitants aged 13 years and older were invited to participate. In the adolescent cohort (Young-HUNT 3), 13- to 19-year-old participants were included. The adolescents completed a comprehensive, selfadministered questionnaire about their health and lifestyle during a school lesson. Participants aged 20 or more were invited to participate in the adult cohort, HUNT 3. Parental and adolescent data were merged, through the Norwegian family register, using the 11-digit personal number by which every citizen in Norway is registered. The design was crosssectional. The HUNT three study is described in more detail

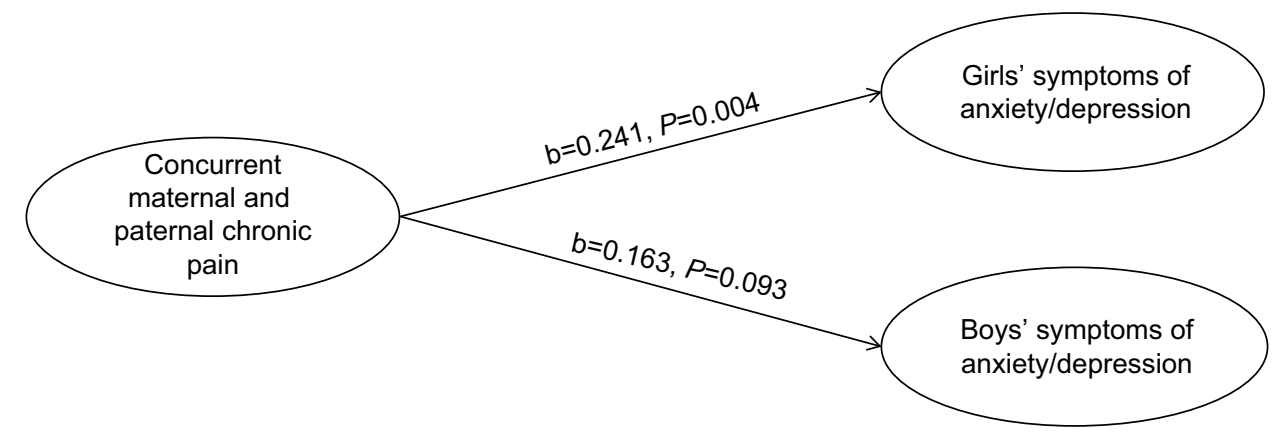

Figure I Concurrent maternal and paternal chronic pain and the offspring's symptoms of anxiety and depression presented with standardized coefficients and $P$-values. Note: Adjusted for the offspring age and parental symptoms of anxiety and depression. 
in previous publications ${ }^{45,46}$ and an English translation of the questionnaire is available at http://www.ntnu.edu/hunt/ data/que.

\section{Participants}

In the HUNT 3 study, there were 8,200 adolescents (78\% of those invited in Young-HUNT) and 50,839 adults (attendance rate of 54\%). The present sample consisted of adolescents in Young-HUNT who had both parents participating in the adult HUNT study $(n=3,436)$. Due to low attendance, participants who were $12(n=19), 19(n=157)$, and $20(n=33)$ were excluded from the analyses. As a result, the sample consisted of 3,227 adolescents aged 13-18 years, divided into four groups according to their parental chronic pain statuses; 608 (20\%) had mothers with chronic pain (M-group), 495 (16\%) had fathers with chronic pain (F-group), and 230 (7\%) had both parents who reported chronic pain (MF-group). The reference group consisted of 1,740 (57\%) adolescents who had parents without chronic pain. There were 154 adolescents who had missing data on parental chronic pain items. For girls $(n=1,594)$, the mean age (SD) was 15.7 (1.67) years and, for boys $(n=1,633)$, it was 15.8 (1.62) years. The number of girls and boys in each group according to parental chronic pain is presented in Tables 1 and 2, respectively. In total, the present study included information from 9,681 individuals (adolescents, mothers, and fathers). A more detailed description of the sample is provided in Kaasbøll et al. ${ }^{7}$

\section{Measures}

\section{Parental variables}

Parental chronic pain was measured by combining the item "Do you have physical pain now that has lasted more than 6 months?" ("No/"Yes") with a pain-rating scale, including six response categories for the item "How strong has your physical pain been during the last 4 weeks?", ranging from no pain (0) to very strong pain (5). The Verbal Rating Scale (VRS) is a commonly used pain-rating scale recommended as a global measurement of the pain severity. ${ }^{47}$ A cutoff point was set at the midpoint of the scale (no to mild vs moderate to very severe pain) because this has been useful in identifying people with clinically significant pain. ${ }^{48-51}$ Therefore, the combination of reporting pain lasting more than 6 months and moderate/severe/very severe pain during the past month made the case for ascertaining parental chronic pain. Maternal chronic pain was defined as pain of moderate to severe intensity lasting for more than 6 months $(n=838)$. The control group with no chronic pain included mothers who reported low levels of pain intensity that has lasted more than 6 months

Table I Girls' social competence, anxiety, and depression and parental anxiety and depression, according to parental chronic pain status

\begin{tabular}{|c|c|c|c|c|c|c|c|c|c|c|c|c|}
\hline & \multicolumn{3}{|c|}{$\begin{array}{l}\text { Girls of mothers with } \\
\text { chronic pain }\end{array}$} & \multicolumn{3}{|c|}{$\begin{array}{l}\text { Girls of fathers with } \\
\text { chronic pain }\end{array}$} & \multicolumn{3}{|c|}{$\begin{array}{l}\text { Girls of mothers and } \\
\text { fathers with chronic } \\
\text { pain }\end{array}$} & \multicolumn{3}{|c|}{ Reference $^{d}$} \\
\hline & $\mathbf{n}$ & Mean & SD & $\mathbf{n}$ & Mean & SD & $\mathbf{n}$ & Mean & SD & $\mathbf{n}$ & Mean & SD \\
\hline Girls' social competence ${ }^{a}$ & 291 & 3.73 & 0.79 & 255 & 3.76 & 0.82 & 106 & 3.55 & 0.98 & 851 & 3.79 & 0.76 \\
\hline Girls' anxiety/depression ${ }^{\mathrm{b}}$ & 291 & 1.62 & 0.63 & 259 & $\mathrm{I} .64$ & 0.62 & 106 & 1.78 & 0.64 & 858 & 1.58 & 0.51 \\
\hline Maternal anxiety/depression ${ }^{c}$ & 287 & 1.68 & 0.33 & 247 & 1.62 & 0.31 & 106 & 1.70 & 0.36 & 852 & 1.60 & 0.28 \\
\hline Paternal anxiety/depression ${ }^{c}$ & 286 & 1.81 & 0.31 & 258 & 1.67 & 0.35 & 106 & 1.69 & 0.29 & 854 & 1.58 & 0.30 \\
\hline
\end{tabular}

Notes: 'Resilience Scale for Adolescents, range I-5, high score represents high levels of social competence. ${ }^{b}$ Hopkins Symptom Checklist, range I-4, high levels represents high levels of symptoms. 'Cohort of Norway Mental Health Index (CONOR-MHI), range, I-4, high levels represents high levels of symptoms. ${ }^{\circledR}$ Reference group; children whose parents do not have chronic pain.

Table 2 Boys' social competence, anxiety, and depression and parental anxiety and depression, according to parental chronic pain status

\begin{tabular}{|c|c|c|c|c|c|c|c|c|c|c|c|c|}
\hline & \multicolumn{3}{|c|}{$\begin{array}{l}\text { Boys of mothers with } \\
\text { chronic pain }\end{array}$} & \multicolumn{3}{|c|}{$\begin{array}{l}\text { Boys of fathers with } \\
\text { chronic pain }\end{array}$} & \multicolumn{3}{|c|}{$\begin{array}{l}\text { Boys of mothers and } \\
\text { fathers with chronic } \\
\text { pain }\end{array}$} & \multicolumn{3}{|c|}{ Reference $^{c}$} \\
\hline & $\mathbf{n}$ & Mean & SD & $\mathbf{n}$ & Mean & SD & $\mathbf{n}$ & Mean & SD & $\mathbf{n}$ & Mean & SD \\
\hline Boys' social competence ${ }^{a}$ & 302 & 4.03 & 0.67 & 222 & 3.91 & 0.81 & 120 & 4.05 & 0.76 & 840 & 3.91 & 0.78 \\
\hline Boys' anxiety/depression ${ }^{\mathrm{b}}$ & 302 & 4.03 & 0.67 & 222 & 3.91 & 0.81 & 120 & 4.05 & 0.76 & 840 & 3.91 & 0.78 \\
\hline Maternal anxiety/depression ${ }^{c}$ & 306 & 1.68 & 0.32 & 228 & 1.62 & 0.35 & 119 & 1.77 & 0.38 & 861 & 1.58 & 0.24 \\
\hline Paternal anxiety/depression ${ }^{c}$ & 307 & 1.60 & 0.33 & 229 & 1.67 & 0.34 & 124 & 1.66 & 0.32 & 861 & 1.58 & 0.29 \\
\hline
\end{tabular}

Notes: aResilience Scale for Adolescents, range I-5, high score represents high levels of social competence. ${ }^{b}$ Hopkins Symptom Checklist, range I-4, high levels represents high levels of symptoms. 'Cohort of Norway Mental Health Index (CONOR-MHI), range, I-4, high levels represents high levels of symptoms. ${ }^{\mathrm{d}}$ Reference group; children whose parents do not have chronic pain. 
$(n=290)$, and mothers who reported pain of less than 6 months duration of either moderate to severe levels of pain intensity $(n=334)$, or low pain intensity $(n=1,519)$. Paternal chronic pain was defined as pain of moderate to severe intensity lasting for more than 6 months $(n=725)$. The control group with no chronic pain included fathers who reported low levels of pain intensity that has lasted more than 6 months $(n=323)$, and fathers who reported pain of less than 6 months' duration of either moderate to severe levels of pain intensity $(n=327)$ or low pain intensity $(n=1,640)$. Parental symptoms of anxiety and depression were measured by the Cohort of Norway Mental Health Index (CONOR-MHI), which includes seven questions on various aspects of mental distress. The CONOR-MHI are partly modified from the General Health Questionnaire-GHQ ${ }^{52}$ and the Hopkins Symptom Check List (HSCL). ${ }^{53}$ The CONOR-MHI items include "Have you, in the last 2 weeks, felt "Nervous and unsettled", "Troubled by anxiety", "Secure and calm", "Irritable", "Happy and optimistic", "Sad/depressed", or "Lonely"?" Each question has four answer categories, ranging from "No" (1) to "Very" (4). The scale has demonstrated good psychometric properties in large population surveys, ${ }^{54,55}$ and a factor analysis suggested that it measures a factor of the mental health status, including both anxiety and depression. ${ }^{55}$ In the current study, the Cronbach's $\alpha$ for maternal and paternal CONOR-MHI were 0.84 and 0.82 , respectively.

The socioeconomic status was measured by the highest level of education attained for the parents, which was obtained from the National Education Database (NUDB). For the current analyses, data from 2008 were used. Educational attainments were classified into the following three levels: compulsory education ( $<10$ years), upper secondary education (10-12 years), and higher-level (tertiary) education $(\geq 13$ years). The self-reported organ-specific diseases included the following: myocardial infarction (heart attack); angina pectoris (chest pain); other heart disease; stroke/brain hemorrhage; kidney disease; asthma; chronic bronchitis; emphysema or chronic obstructive pulmonary disease; diabetes; cancer; and epilepsy. Responses to these questions were dichotomized into no or at least one disease.

\section{Adolescent variables}

Social competence was measured by one subscale from the Resilience Scale for Adolescents (READ), ${ }^{56}$ which consists of the following four items: "I make others feel comfortable around me"; "I easily find new friends"; "I am good at talking to new people"; and "I always find something fun to talk about". The responses ranged from totally agree (1) to totally disagree (5). Social competence represents one of the five dimensions of READ. The READ has been shown to possess adequate psychometric properties. ${ }^{17,57-60}$ In the present study, Cronbach's $\alpha$ for the social competence scale was 0.83 for girls and 0.81 for boys.

The adolescents' symptoms of anxiety and depression were measured by the SCL-5, which is based on a short version of the HSCL (SCL-25). ${ }^{61}$ The SCL-5 includes five items addressing how the adolescents felt in the previous 14 days, with responses ranging from not bothered (1) to very bothered (4). Anxiety problems included "Constantly afraid and anxious," "Felt tense or uneasy," and "Worried too much about various things". Depressive problems included "Felt hopelessness when you think of the future" and "Felt dejected or sad". This measurement has been demonstrated to be reliable in previous studies. ${ }^{61}$ Cronbach's $\alpha$ for the SCL-5 scale was 0.82 in the current study.

The adolescent's cohabitation status was classified as "living with one parent" or "living with both parents".

\section{Statistical analyses}

In the HUNT study, short forms of established measurement scales were used to reduce potential respondent fatigue. However, the validity of the original scales may not apply to shortened scales. Therefore, confirmatory factor analysis (CFA; the measurement model) was conducted prior to testing the hypothesized structural mediation models. To explore sex differences, we estimated multi-group models distinguishing between girls and boys. Scalar measurement invariance was tested (unstandardized factor loadings were held invariant across girls and boys) to ensure the comparability of the girls' and boys' scores on the latent variables. Cronbach's $\alpha$ was used to test the reliability and internal consistency of the variables.

To examine the adolescents' levels of social competence, one-way ANOVA with the Hochberg post hoc correction was used. Independent samples $t$-test was used to investigate the differences between girls and boys in the different groups according to the parental chronic pain status. Cohen's $d$ was used as a measure of the effect size.

Two structural models of direct and indirect associations between parental chronic pain and offspring anxiety/ depression were tested (see Figures 1-3). When estimating the indirect paths in the mediation models, we followed recommended procedures with 1,000 bootstrap samples ${ }^{62}$ to avoid assuming normally distributed data and obtain unbiased values. Multi-group mediation models were used to test moderated mediation. The ratio of sample size to the number of parameters estimated was $1,529 / 141=10.84$ for girls and $1,544 / 141=10.95$ for boys, indicating that 


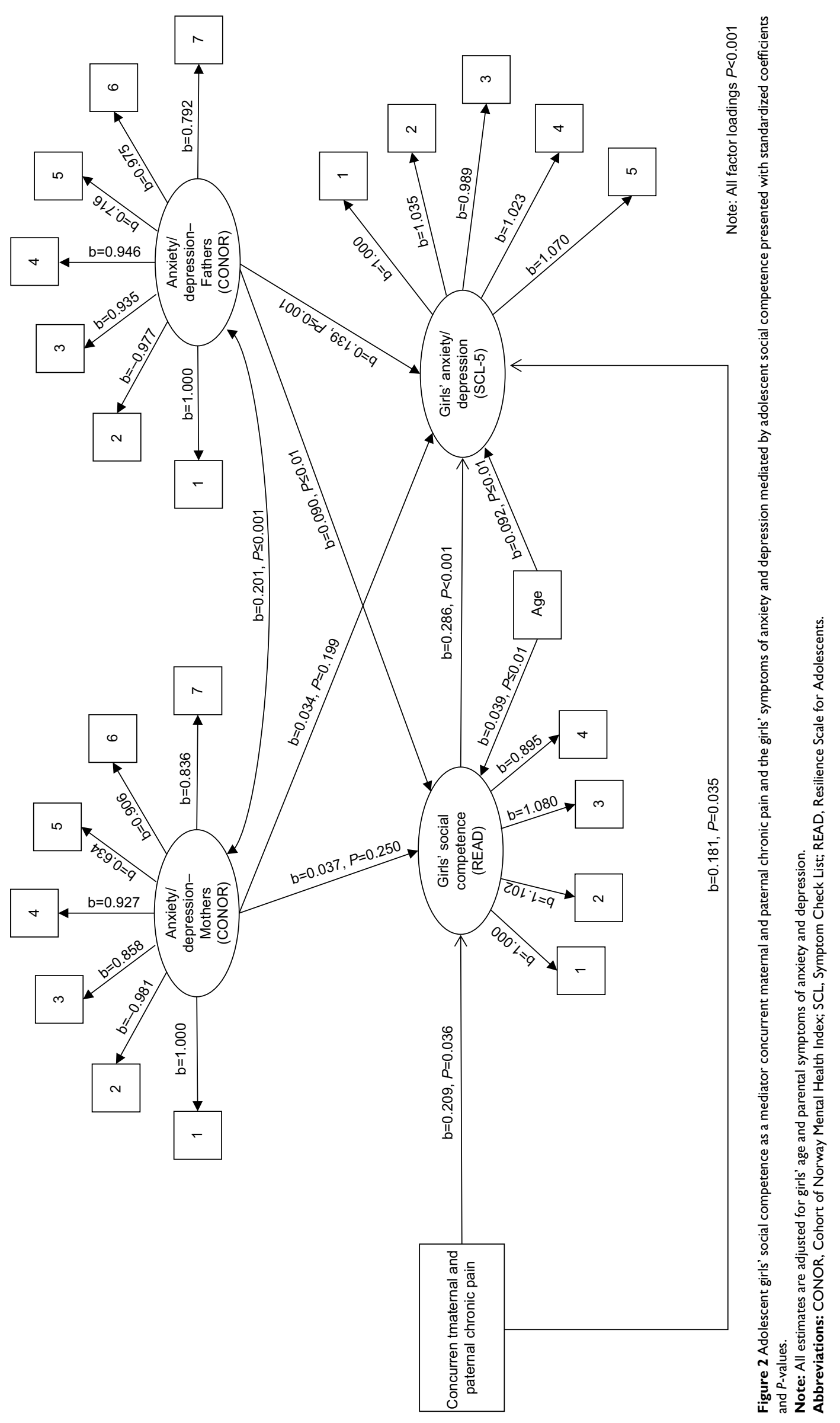




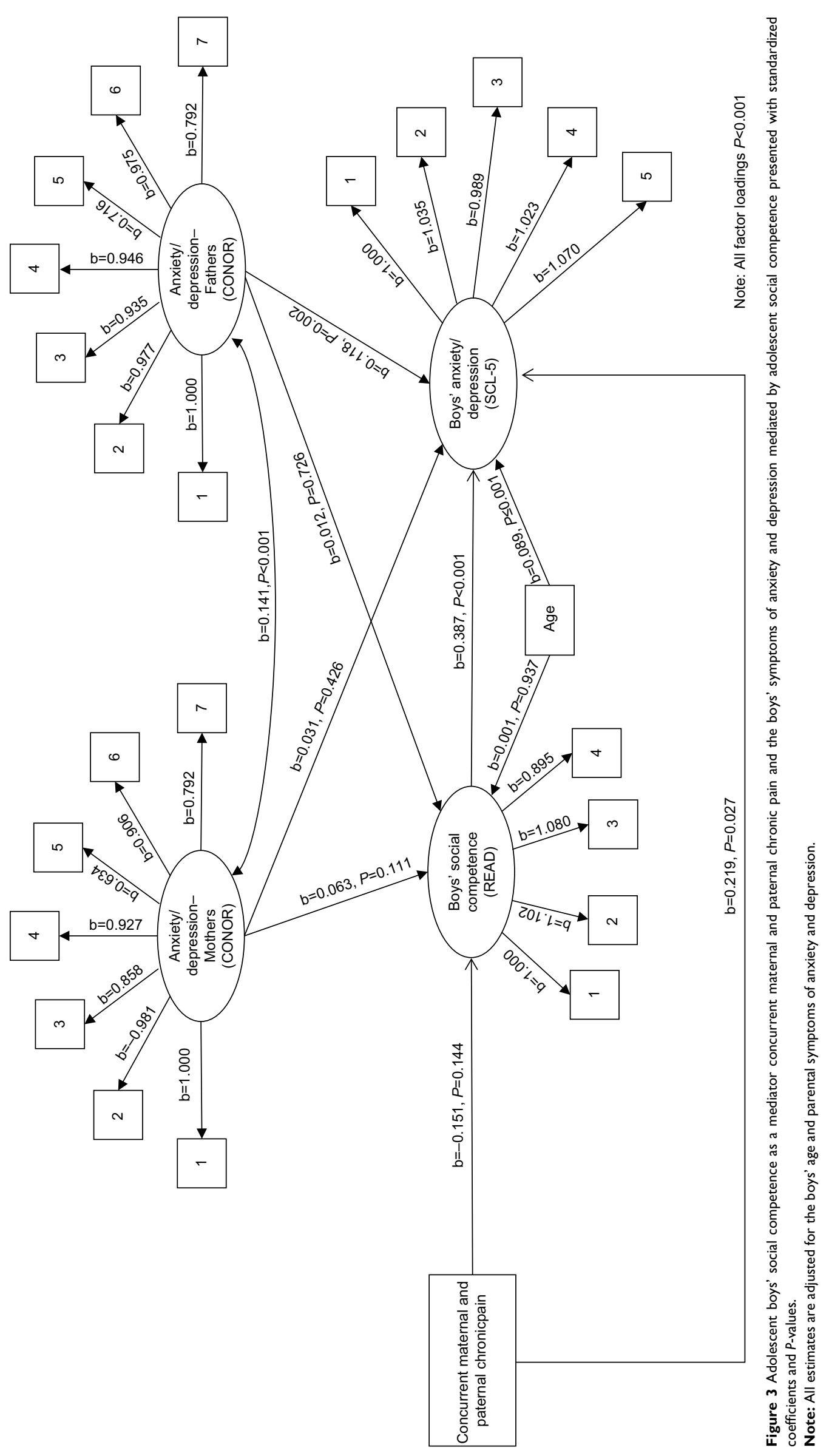


the sample size is sufficient for the analyses conducted. ${ }^{63}$ Notably, we tested a mediation model, based on existing theories and empirical studies, which is in line with suggestions by Hayes. ${ }^{64}$ Due to the cross-sectional design of the present study, we did not test the causal relationships, and the results indicate associations between parental and child factors that could be bidirectional.

Although the tested models were not nested, decomposable fit indices were reported for the measurement and path models. Several fit indices were examined. A non-significant chi-square statistic, CFI- and TLI-values $>0.95$, and RMSEA-values $<0.06$ indicate a good model fit. ${ }^{65}$ The models were estimated with the weighted least square parameter with the mean and variance adjustment estimator (WLSMV) due to the categorical and non-normal nature of the indicators.

We adjusted for adolescent age and parental symptoms of anxiety and depression in all paths because these factors were weakly, but significantly, associated with the dependent variable. Parental education, parental organ-specific illness and the child cohabitation status were not significantly associated with our dependent variable, and we did not adjust for these variables. The sample size in the present study was large. However, the magnitude of effects is expected to be small because most participants are healthy in community samples. There were low rates of missing values in the data set $(\leq 4.8 \%)$. All missing values were handled by the full information maximum likelihood procedure (FIML) in Mplus. Twosided $P$-values $<0.05$ were considered statistically significant. Structural equation modeling was done using Mplus 7.1166 and other analyses were conducted in SPSS.

\section{Ethics}

Written consent to participate in the HUNT study was provided by all participants and by the parents of children younger than age 16 . The present study complied with the Declaration of Helsinki principles and was approved by the Regional Committee for Medical Research Ethics (REK; reference number 4.2008.664) and by the Norwegian Social Science Data Services (NSD).

\section{Results}

The mean values (SD) of adolescents' social competence, symptoms of anxiety and depression, and parental levels of anxiety and depression symptoms are presented in Tables 1 and 2, according to the parental chronic pain status, for girls and boys. Further characteristics of the target sample, such as the parental age, education, organ-specific illnesses, cohabitation status, and the child's symptoms of anxiety and depression (SCL-5), were described in a previous publication. ${ }^{7}$ In summary, parental chronic pain was associated with higher levels of parental symptoms of anxiety and depression, lower levels of education, organ-specific illness, paternal older age, and dissolved family structure.

\section{Parental chronic pain and social competence in girls and boys}

In the general sample, one-way ANOVA indicated that there were significant main effects of parental chronic pain on social competence for girls $(\mathrm{F}[3,1499]=3.12, P=0.025)$ and boys $(\mathrm{F}[3,1499]=2.79, P=0.040)$. Post hoc analyses using the Hochberg post hoc correction for significance indicated that, for girls, the average score on self-reported social competence was significantly lower among girls in the MF-group (mean difference $=-0.24, P=0.019$ ) compared with girls in the reference group. For boys, post hoc tests identified no significant group differences.

Independent samples $t$-test indicated that girls reported significantly lower scores than boys on social competence in the M-group: $t(561)=-5.10, P<0.001$ (Cohen's $d=-0.41)$, MF-group: $t(198)=-4.22, P<0.001$ (Cohen's $d=-0.57$ ) and reference group: $t(1,689)=-3,19, P=0.001$ (Cohen's $d=-0.16)$. Although not significant, there was a tendency toward lower levels of social competence for girls in the F-group $t(475)=-1.92, P=0.056$ (Cohen's $d=-0.18$ ) compared with boys.

\section{Measurement model}

Except for a significant chi-squared test, which was expected due to the large sample size, the fit indices for the model were $\operatorname{good}\left(\chi^{2}[513, \mathrm{~N}=3,227]=3,735, P<0.001\right.$; $\mathrm{CFI}=0.945$; $\mathrm{TLI}=0.946$; RMSEA=0.062). Furthermore, indicating an acceptable model fit, the factor loadings were satisfactory and statistically significant $(P<0.05)$ for all indicators, as shown in Table S1. Correlations between variables are shown in Table 3.

\section{Parental chronic pain and the offspring's symptoms of anxiety and depression}

An initial path model showed that there were no significant associations between parental chronic pain and symptoms of anxiety and depression among children in the $\mathrm{M}$ - and F-groups. However, concurrent maternal and paternal chronic pain was significantly associated with symptoms of anxiety and depression in adolescent offspring. Therefore, we analyzed a new model with only the paths associating the MF- 
Table 3 Correlations between variables (standard errors in parentheses), girls below the diagonal and boys above the diagonal

\begin{tabular}{|l|l|l|l|l|l|l|}
\hline Variables $^{\mathbf{a}}$ & $\mathbf{I}$ & $\mathbf{2}$ & $\mathbf{3}$ & $\mathbf{4}$ & $\mathbf{5}$ & $\mathbf{6}$ \\
\hline I. Child age & - & $0.169(0.029)$ & $0.003(0.028)^{\mathrm{ns}}$ & $0.085(0.048)^{\mathrm{ns}}$ & $-0.020(0.028)^{\mathrm{ns}}$ & $-0.047(0.028)^{\mathrm{ns}}$ \\
\hline $\begin{array}{l}\text { 2. Child symptoms of anxiety } \\
\text { and depression (SCL-5) }\end{array}$ & $0.228(0.028)$ & - & $0.382(0.028)$ & $0.107(0.056)^{\mathrm{ns}}$ & $0.083(0.034)$ & $0.134(0.034)$ \\
\hline 3. Child social competence & $0.087(0.027)$ & $0.322(0.028)$ & - & $-0.086(0.052)^{\mathrm{ns}}$ & $0.057(0.03 \mathrm{I})$ & $0.018(0.032)^{\mathrm{ns}}$ \\
\hline $\begin{array}{l}\text { 4. Concurrent maternal and } \\
\text { paternal chronic pain }\end{array}$ & $0.04 \mathrm{I}(0.046)^{\mathrm{ns}}$ & $0.160(0.053)$ & $0.067(0.03 \mathrm{I})$ & - & $0.258(0.05 \mathrm{I})$ & $0.227(0.050)$ \\
\hline $\begin{array}{l}\text { 5. Maternal symptoms of anxiety } \\
\text { and depression (CONOR-MHI) }\end{array}$ & $-0.04 \mathrm{I}(0.028)^{\mathrm{ns}}$ & $0.094(0.032)$ & $0.067(0.03 \mathrm{I})$ & $0.107(0.053)$ & - & $0.224(0.032)$ \\
\hline $\begin{array}{l}\text { 6. Paternal symptoms of anxiety } \\
\text { and depression (CONOR-MHI) }\end{array}$ & $-0.04 \mathrm{I}(0.028)^{\mathrm{ns}}$ & $0.199(0.03 \mathrm{I})$ & $0.102(0.030)$ & $0.153(0.054)$ & $0.253(0.029)$ & - \\
\hline
\end{tabular}

Notes: ${ }^{a} A$ Il correlations are statistically significant $(P<0.05)$, except if otherwise indicated by superscript indicators (ns=non-significant). ${ }^{b} \mathrm{Hopkins}$ Symptom Checklist, range $\mathrm{I}-4$, high levels represents high levels of symptoms. 'Resilience Scale for Adolescents, range I-5, high scores represent high levels of social competence. ${ }^{\mathrm{d} C o h o r t}$ of Norway Mental Health Index (CONOR-MHI), range, I-4, high levels represent high levels of symptoms.

group with offspring variables while adjusting for offspring age and parental anxiety/depression (Figure 1). Model fit indices were good for this model $\left(\chi^{2}[421, \mathrm{~N}=3,073]=3,254\right.$, $P<0.001 ; \mathrm{CFI}=0.942 ; \mathrm{TLI}=0.943 ; \mathrm{RMSEA}=0.066$ ). Although the path from parental chronic pain to boys' symptoms of anxiety and depression was not significant, this path was not significantly different for girls and boys (Wald test of parameter constraints $[1]=0.372, P=0.540$ ). When constraining the parameters to be equal for girls and boys, all paths were significant, indicating that concurrent maternal and paternal chronic pain was associated with symptoms of anxiety and depression in offspring of both sexes.

\section{Role of social competence in the associations between parental chronic pain and offspring symptoms of anxiety and depression}

Furthermore, when including the indirect paths, fit indices were acceptable to good $\left(\chi^{2}[597, \mathrm{~N}=3,073]=3,692\right.$, $P<0.001$; $\mathrm{CFI}=0.945$; TLI $=0.945$; $\mathrm{RMSEA}=0.058$ ). For both girls and boys, the direct paths from concurrent maternal and paternal chronic pain to adolescent symptoms of anxiety/depression were still significant when including social competence as a potential mediator (Figures 2 and 3 ). Furthermore, the results showed that adolescent social competence was significantly associated with adolescent anxiety/depression for both sexes. However, parental chronic pain was significantly associated with offspring social competence for girls but not for boys. In fact, for girls, the indirect path from parental chronic pain to offspring symptoms of anxiety and depression via offspring social competence was significant (b $[95 \% \mathrm{CI}]=0.060[-0.002$, 0.115 ], $P=0.043$ ), whereas this indirect path was not significant for boys (b $[95 \% \mathrm{CI}]=-0.059[-0.145,0.018]$, $P=0.146)$. The direct effects were not significantly different for girls and boys (b [95\% CI] $=-0.038[-0.302,0.205]$, $P=0.769$ ), whereas the indirect effect was significantly different (b $[95 \% \mathrm{CI}]=0.118[0.020,0.211], P=0.015$ ). This indicates that social competence partially mediated the association between concurrent maternal and paternal chronic pain and the offspring's symptoms of anxiety and depression for girls, but not for boys. The magnitude of the direct effect between concurrent maternal and paternal chronic pain and boys' anxiety and depression increases and becomes significant with the inclusion of boys' social competence in the model. Further, parental chronic pain is positively (although non-significantly) related to high levels of social competence in boys.

\section{Discussion}

In the present study, we explored the role of social competence in the associations between parental chronic pain and offspring internalizing symptoms. The most prominent finding was that the association between concurrent maternal and paternal chronic pain and the offspring's symptoms of anxiety and depression was partially mediated by low social competence for girls, but not for boys. For both girls and boys, there was a direct effect of concurrent maternal and paternal chronic pain on the offspring's symptoms of anxiety and depression. Furthermore, low levels of social competence were associated with increased scores for anxiety and depressive symptoms for both sexes. Chronic pain in only one parent (mother or father) was not significantly associated with the offspring's levels of social competence or symptoms of anxiety and depression.

\section{Parental chronic pain and symptoms of anxiety and depression in offspring}

As reported in Kaasbøll et al, ${ }^{7}$ the results indicate an association between concurrent maternal and paternal chronic 
pain and symptoms of anxiety and depression for both girls and boys. Furthermore, chronic pain in one parent was not associated with symptoms of anxiety and depression and social competence in the offspring. Although this topic was not directly investigated in the present study, we speculate that the presence of one healthy parent may buffer the adverse effect of chronic pain in the family. One might expect that the overall burden in the families in which both parents had chronic pain of moderate to high intensity is higher than in families where only one parent suffer from chronic pain. It is possible that the presence of one healthy parent may compensate for the potential strain created by chronic pain in the other parent, making the child less vulnerable to distress. Findings from an adjacent research area (ie, parental depression) indicate that a healthy father may attenuate the adverse effects of maternal depression on child health by increasing his role as a caretaker and by providing additional support to the child's mother. ${ }^{67-70}$ Further research is needed to disentangle such potential mechanisms.

\section{Parental chronic pain and social competence in offspring}

In line with previous studies, ${ }^{16,17}$ we found that boys in all groups designed according to parental chronic pain status reported higher levels of social competence compared with girls. In this study, girls in the MF-group had lower levels of social competence compared with girls in the reference group, whereas no significant differences were found for boys. In contrast to previous studies indicating that maternal or paternal chronic pain was associated with reduced levels of social competence, ${ }^{26,28}$ our results indicated that having one parent with chronic pain was not associated with reduced levels of social competence in the offspring. The discrepancy in results could be explained by the use of parent/teacher report vs self-report; pre-adolescents vs adolescents as a target group; clinical vs population sample, and one vs two parents with chronic pain as exposure variables in the previous $^{26,28}$ and current studies, respectively.

\section{Associations between adolescents' social competence and symptoms of anxiety and depression}

As reported by numerous studies, ${ }^{16-18}$ we found that lower levels of social competence were strongly associated with increasing symptoms of anxiety and depression for both girls and boys. This may indicate that social competence can contribute to the development of such symptoms, but it is also possible that offspring's symptoms of anxiety and depression may cause reduced levels of social competence. Adolescents with higher levels of internalizing symptoms may have poorer social competence because of their mood, apathy, or a negative attribution style. ${ }^{71}$ Moreover, the relationship between social competence and internalizing problems could be the result of a reciprocal process. ${ }^{22}$

\section{Social competence as a mediator for girls}

The results indicated that low social competence partly mediated the association between concurrent maternal and paternal chronic pain and symptoms of anxiety and depression for girls, but not for boys. The potential pathway of concurrent maternal and paternal chronic pain that reduced the levels of social competence and symptoms of anxiety and depression in girls may be influenced by several mechanisms. First, genetic factors ${ }^{22}$ and gene-environment interactions $\mathbf{s}^{42,72}$ may influence the levels of social competence and symptoms of anxiety and depression in the children of parents with chronic pain.

Second, the girls' reduced levels of social competence as well as increased levels of internalizing symptoms may be the result of observational learning ${ }^{36,73}$ because social isolation and emotional symptoms are a major problem for individuals with chronic pain. ${ }^{2,30-32}$ Additionally, parental chronic pain and the frequent comorbid depression is often accompanied by the decreased emotional availability of the parent. This may directly and indirectly affect the quality of family relationships through factors such as poorer parent-child relationships and dysfunctional parenting. ${ }^{74}$ These factors are all associated with lower levels of social competence in the offspring. ${ }^{12}$

Third, girls in the MF-group may be more likely than boys to take on care responsibilities in the home, and previous studies indicate that the experience of being a young carer may be more troublesome for girls than for boys. ${ }^{75,76}$ In a study that explored worries and problems of young carers, ${ }^{75}$ girls reported that relationships with peers were a source of anxiety, especially concerning problems of falling out with friends and worries about not having friends. Furthermore, it is possible that the sex differences in caregiving roles and responsibilities in the home may increase the impact of conditioning and modeling processes for parental painrelated behavior. In addition, it has been suggested that girls, compared with boys, are more sensitive of interpersonal difficulties, including parental stress, chronic illness, and peer rejection, which makes them more susceptible to emotional difficulties. ${ }^{6,77-79}$ 
Fifth, during adolescence, family interactions change to meet the developmental needs of the adolescents for independence and individuation. ${ }^{80}$ Friends, rather than parents, become increasingly important. ${ }^{78,81}$ It is possible that the individuation and separating processes are more demanding for girls than for boys when both parents suffer from chronic pain. Additionally, the increased focus of adolescent girls on relationships may contribute to worries about social approval, abandonment, and the status of their friendships, which may influence their emotional well-being. ${ }^{77}$ Further research could benefit from investigating girls' and boys' caregiving responsibilities and levels of sensitivity toward their parents' pain.

Lastly, in the current study, the magnitude of the direct effect between parental pain and boys' anxiety and depression increased and became significant with the inclusion of boys' social competence in the model. Although not significant, parental chronic pain was positively related to high levels of social competence in boys. One possible explanation could be that social competence is a suppressor variable among boys. Evans and de Souza ${ }^{82}$ suggested that maternal chronic pain may enhance both growth and adversity in many families. Despite its initial counter-intuitiveness, researchers have suggested that high levels of social competence might be both adaptive and maladaptive, ${ }^{83,84}$ in that individuals might be too attentive to the needs of others and thereby overrule their own needs. As social competence is a main element of many prevention/intervention programs, ${ }^{85,86}$ it is essential to nuance the role of social competence and potential sex differences in the context of children as carers.

\section{Limitations and strengths}

A major limitation of the present study was the cross-sectional design, which implies an inability to infer causality. Although this also applies for correlational longitudinal studies, they may indicate causality to a stronger degree. Given solid theory and argument, Hayes ${ }^{64}$ argues for the possibility for examining mediation even with cross-sectional data. Based on the theory and results of previous empirical studies, we assumed that social competence could be affected by both parental chronic pain and offspring's symptoms of anxiety and depression, which is in line with the recommendations by Kline ${ }^{87}$ and Hayes ${ }^{64}$ on performing mediation analysis on cross-sectional data. As all variables in the present study were measured simultaneously, it is not possible to demonstrate temporal precedence. All findings obtained in the present study need to be confirmed in future prospective studies, preferably using longitudinal data with more study periods. ${ }^{88,89}$ However, the results from this study can serve as a basis for constructs worthy of further investigation for a broader understanding of mechanisms involved in the families of chronic pain sufferers. The current study was based solely on adolescent self-reports of social competence. Further studies could benefit from including observational or multi-informant designs. Another limitation is that the adolescents who did not have both parents participating in the HUNT3 study were not included in the main analysis. However, the effect sizes of these differences between groups have previously been reported to be small. ${ }^{90}$

In this study, the most important potential source of information bias is a misclassification of the categorical and dichotomous measures. The case ascertainment of the exposure variable in the present study (ie, parental chronic pain) was based on a combination of two items, including the use of a cutoff level. This approach could introduce misclassification (ie, parents that suffer from chronic pain are classified as pain-free parents and vice versa). However, this type of case ascertainment was previously demonstrated to be a reliable measure of chronic pain that identifies clinical cases of chronic pain and excludes cases that arise from minor accidents. ${ }^{48-51}$ Furthermore, in the present study, the control group (defined as no chronic pain) comprised individuals that reported low or moderate to severe levels of pain intensity of less than 6 months' duration, or low levels of pain intensity lasting for more than 6 months. Therefore, the inclusion criteria for the control group might have contributed a slight underestimation of the associations in the present study, as the control group includes individuals reporting pain of low intensity. However, the inconsistency in the definition of chronic pain in the epidemiological literature ${ }^{91}$ call for further exploration of parental chronic pain of mild vs high intensity and the associations with the adolescent's adjustment.

Despite these limitations, the present study investigated a large population sample, including independent information from children and both their mother and father, which allowed for an examination of the unique contribution of maternal, paternal, and concurrent maternal and paternal chronic pain vs parents without chronic pain. The large sample size also made it feasible to control for possible effects of pain and psychosocial factors associated with chronic pain, including parental symptoms of anxiety and depression. Another advantage of the present study was the employment of SEM, which made it possible to evaluate the measurement error and test the significance of indirect paths using bootstrapping instead of relying on the somewhat outdated Baron and Kenny approach, which is low in power. ${ }^{92}$ Furthermore, we tested for gender differences, which adds to the research literature. 


\section{Clinical and scientific implications}

Despite several studies linking parental chronic pain to outcomes in offspring, very few have examined the potential pathways behind this link. The present study is a starting point for understanding the mechanisms involved in the relationship between parental chronic pain and child outcomes. Our findings show that social competence is a potential pathway from parental pain to internalizing problems in adolescent offspring. Knowledge about the potential maladaptive functioning in offspring, such as of the reduced levels of social competence and internalizing symptoms, is important because the family environment is central in the treatment of chronic pain..$^{93}$ Despite the cross-sectional design of the study, our findings indicate that a possible suggestion for future work may be to explore intervention strategies designed to increase social competence, especially among girls who have two parents with chronic pain. For parents and health-care practitioners, promoting children's social competence could be beneficial and may possibly protect against later symptoms of anxiety and depression. ${ }^{18,22}$ Further research should aim to identify protective factors for internalizing symptoms for girls as well as for boys who are exposed to concurrent maternal and paternal chronic pain.

\section{Conclusion}

The present study addresses gaps in the existent literature by examining links between parental chronic pain, child social competence, and symptoms of anxiety and depression in a large population-based study using latent variable methods. The study provides new information about the role of social competence in the relationship between parental chronic pain and symptoms of anxiety and depression in the offspring, indicating that social competence in girls is compromised in the presence of concurrent maternal and paternal chronic pain, which could be a risk factor for internalizing symptoms.

\section{Acknowledgments}

The Nord-Trøndelag Health Study (The HUNT Study) is a collaboration between the HUNT Research Center, The Faculty of Medicine, Norwegian University of Science and Technology (NTNU); The Norwegian Institute of Public Health; and Nord-Trøndelag County Council. Financial support was provided by The Regional Center for Child and Youth Mental Health and Child Welfare (RKBU) of Central Norway, Faculty of Medicine, Norwegian University of Science and Technology, Trondheim.

\section{Disclosure}

The authors report no conflicts of interest in this work.

\section{References}

1. Breivik H, Collett B, Ventafridda V, Cohen R, Gallacher D. Survey of chronic pain in Europe: prevalence, impact on daily life, and treatment. Eur J Pain. 2006;10(4):287-333.

2. Roy R. The impact of chronic pain on marriage and family. In: Roy R, editor. Chronic Pain and Family: a Clinical Perspective. New York, NY: Springer; 2006:16-28.

3. Silver JK. Chronic Pain and the Family: a New Guide. Cambridge, MA: Harvard University Press; 2004

4. Romano JM, Turner JA, Jensen MP. The family environment in chronic pain patients: comparison to controls and relationship to patient functioning. J Clin Psychol Med Settings. 1997;4(4):383-395.

5. Barkmann C, Romer G, Watson M, Schulte-Markwort M. Parental physical illness as a risk for psychosocial maladjustment in children and adolescents: epidemiological findings from a national survey in Germany. Psychosomatics. 2007;48(6):476-481.

6. Sieh DS, Meijer AM, Oort FJ, Visser-Meily JM, van der Leij DA Problem behavior in children of chronically ill parents: a meta-analysis. Clin Child Fam Psychol Rev. 2010;13(4):384-397.

7. Kaasbøll J, Lydersen S, Indredavik MS. Psychological symptoms in children of parents with chronic pain-the HUNT study. Pain 2012;153(5):1054-1062

8. Umberger W. Children of parents with chronic noncancer pain: a comprehensive review of the literature. Journal of Child and Adolescent Psychiatric Nursing. 2014;27(1):26-34p.

9. Higgins KS, Birnie KA, Chambers CT, et al. Offspring of parents with chronic pain: a systematic review and meta-analysis of pain, health, psychological, and family outcomes. Pain. 2015;156(11):2256-2266.

10. Roustit C, Campoy E, Chaix B, Chauvin P. Exploring mediating factors in the association between parental psychological distress and psychosocial maladjustment in adolescence. Eur Child Adolesc Psychiatry. 2010;19(7):597-604.

11. Burt KB, Obradović J, Long JD, Masten AS. The interplay of social competence and psychopathology over 20 years: testing transactional and cascade models. Child Dev. 2008;79(2):359-374.

12. Semrud-Clikeman M. Social Competence in Children. New York, NY Springer; 2007.

13. Bukowski WM, Rubin KH, Parker JG. Social competence: childhood and adolescence. In: Smelser NJ, Baltes PB, editors. International Encyclopedia of the Social \& Behavioral Sciences. Oxford: Pergamon; 2001:14258-14264

14. Merrell KW. Assessment of social skills and peer relationships. In: Whitcomb SA, editor. Behavioral, Social, and Emotional Assessment of Children and Adolescents. Mahwah, NJ: Lawrence Erlbaum Associates, Inc; 1999:313-335.

15. Forehand R, Neighbors B, Wierson M. The transition to adolescence: the role of gender and stress in problem behavior and competence. $J$ Child Psychol Psychiatry. 1991;32(6):929-937.

16. Skrove M, Romundstad P, Indredavik MS. Resilience, lifestyle and symptoms of anxiety and depression in adolescence: the Young-HUNT study. Soc Psychiatry Psychiatr Epidemiol. 2013;48(3):407-416

17. von Soest T, Mossige S, Stefansen K, Hjemdal O. A Validation Study of the Resilience Scale for Adolescents (READ). J Psychopathol Behav Assess. 2010;32(2):215-225.

18. Hjemdal O, Aune T, Reinfjell T, Stiles TC, Friborg O. Resilience as a predictor of depressive symptoms: a correlational study with young adolescents. Clin Child Psychol Psychiatry. 2007;12(1):91-104.

19. Bagwell CL, Newcomb AF, Bukowski WM. Preadolescent friendship and peer rejection as predictors of adult adjustment. Child Dev. 1998;69(1):140-153.

20. Parker JG, Asher SR. Peer relations and later personal adjustment: are low-accepted children at risk? Psychol Bull. 1987;102(3):357-389. 
21. Masten AS, Burt KB, Coatsworth JD. Competence and psychopathology in development. In: Cicchetti D, Cohen DJ, editors. Developmental Psychopathology: Risk, Disorder, and Adaptation. New York, NY: Wiley; 2006:696-738.

22. Bornstein MH, Hahn CS, Haynes OM, Competence S. Social competence, externalizing, and internalizing behavioral adjustment from early childhood through early adolescence: developmental cascades. Dev Psychopathol. 2010;22(4):717-735.

23. Masten AS, Cicchetti D, Cascades D. Developmental cascades. Dev Psychopathol. 2010;22(3):491-495.

24. Obradović J, Hipwell A. Psychopathology and social competence during the transition to adolescence: the role of family adversity and pubertal development. Dev Psychopathol. 2010;22(3):621-634.

25. Korhonen M, Luoma I, Salmelin RK, Helminen M, Kaltiala-Heino $\mathrm{R}$, Tamminen T. The trajectories of child's internalizing and externalizing problems, social competence and adolescent self-reported problems in a Finnish normal population sample. Sch Psychol Int. 2014;35(6):561-579.

26. Chun DY, Turner JA, Romano JM. Children of chronic pain patients: risk factors for maladjustment. Pain. 1993;52(3):311-317.

27. Dura JR, Beck SJ. A comparison of family functioning when mothers have chronic pain. Pain. 1988;35(1):79-89.

28. Evans S, Keenan TR, Shipton EA. Psychosocial adjustment and physical health of children living with maternal chronic pain. J Paediatr Child Health. 2007;43(4):262-270.

29. Kaasbøll J, Ranøyen I, Nilsen W, Lydersen S, Indredavik MS. Associations between parental chronic pain and self-esteem, social competence, and family cohesion in adolescent girls and boys-family linkage data from the HUNT study. BMC Public Health. 2015;15(1):817.

30. Roy R. Impact of parental illness and pain on children. In: Roy R, editor. Social Relations and Chronic Pain. New York, NY: Kluwer Academic Publishers Group; 2001.

31. Roy R. Psychosocial Interventions for Chronic Pain: in Search of Evidence. New York, NY: Springer; 2008.

32. Moulin DE, Clark AJ, Speechley M, Morley-Forster PK. Chronic pain in Canada--prevalence, treatment, impact and the role of opioid analgesia. Pain Res Manag. 2002;7(4):179-184.

33. Turk DC, Flor H, Rudy TE. Pain and families. I. Etiology, maintenance, and psychosocial impact. Pain. 1987;30(1):3-27.

34. Litman TJ. The family as a basic unit in health and medical care: a social-behavioral overview. Soc Sci Med. 1974;8(9-10): 495-519.

35. White CP, Mendoza J, White MB, Bond C. Chronically ill mothers experiencing pain: relational coping strategies used while parenting young children. Chronic Illn. 2009;5(1):33-45.

36. Stone AL. Social learning pathways in the relation between parental chronic pain and daily pain severity and functional impairment in adolescents with functional abdominal pain. Pain. 2017.

37. Goldstein S, Brooks RB. Handbook of Resilience in Children. New York, NY: Springer; 2006.

38. Repetti RL, Taylor SE, Seeman TE. Risky families: family social environments and the mental and physical health of offspring. Psychol Bull. 2002;128(2):330-366.

39. Parke RD, Simpkins SD, McDowell DJ, et al. Relative contributions of families and peers to children's social development. In: Smith PK, Hart CH, editors. Handbook of Childhood Social Development. London: Blackwell Publishing; 2004:156-177.

40. Aronen ET, Kurkela SA. The predictors of competence in an adolescent sample: A 15-year follow-up study. Nord J Psychiatry. 1998;52(3):203-212.

41. Leino-Arjas P, Hänninen K, Puska P. Socioeconomic variation in back and joint pain in Finland. Eur J Epidemiol. 1998;14(1):79-87.

42. Korhonen M, Luoma I, Salmelin R, Tamminen T. Maternal depressive symptoms: associations with adolescents' internalizing and externalizing problems and social competence. Nord J Psychiatry. 2014;68(5):323-332.
43. Cumsille PE, Epstein N. Family cohesion, family adaptability, social support, and adolescent depressive symptoms in outpatient clinic families. Journal of Family Psychology. 1994;8(2):202-214.

44. Goodman SH, Brogan D, Lynch ME, Fielding B. Social and emotional competence in children of depressed mothers. Child Dev. 1993;64(2):516-531.

45. Holmen TL, Bratberg G, Krokstad S, et al. Cohort profile of the YoungHUNT Study, Norway: a population-based study of adolescents. Int $J$ Epidemiol. 2014;43(2):536-44-544.

46. Langhammer A, Krokstad S, Romundstad P, Heggland J, Holmen J. The HUNT study: participation is associated with survival and depends on socioeconomic status, diseases and symptoms. BMC Med Res Methodol. 2012;12(1): 143 .

47. von Korff M, Jensen MP, Karoly P. Assessing global pain severity by self-report in clinical and health services research. Spine. 2000;25(24):3140-3151.

48. Landmark T, Romundstad P, Borchgrevink PC, Kaasa S, Dale O. Associations between recreational exercise and chronic pain in the general population: evidence from the HUNT 3 study. Pain. 2011;152(10):2241-2247.

49. Jensen MP, Turner JA, Romano JM, Fisher LD. Comparative reliability and validity of chronic pain intensity measures. Pain. 1999;83(2):157-162.

50. Jensen MK, Sjøgren P, Ekholm O, Rasmussen NK, Eriksen J. Identifying a long-term/chronic, non-cancer pain population using a onedimensional verbal pain rating scale: an epidemiological study. Eur $J$ Pain. 2004;8(2):145-152.

51. Landmark T, Romundstad P, Dale O, Borchgrevink PC, Kaasa S. Estimating the prevalence of chronic pain: validation of recall against longitudinal reporting (the HUNT pain study). Pain. 2012;153(7):1368-1373.

52. Goldberg DP. The Detection of Psychiatric Illness by Questionnaire: a Technique for the Identification and Assessment of Non-Psychotic Psychiatric Illness. London: Oxford University Press; 1972.

53. Derogatis LR, Lipman RS, Rickels K, Uhlenhuth EH, Covi L. The Hopkins Symptom Checklist (HSCL): a self-report symptom inventory. Behav Sci. 1974;19(1):1-15.

54. Bramness JG, Walby FA, Hjellvik V, Selmer R, Tverdal A. Self-reported mental health and its gender differences as a predictor of suicide in the middle-aged. Am J Epidemiol. 2010;172(2):160-166.

55. Søgaard AJ. A comparison of the CONOR Mental Health Index to the HSCL-10 and HADS. Norsk epidemiologi. 2003;13(2):279-284.

56. Hjemdal O, Friborg O, Stiles TC, Martinussen M, Rosenvinge JH. A new scale for adolescent resilience: grasping the central protective resources behind healthy development. Measurement and Evaluation in Counseling and Development. 2006;39(2):84-96.

57. Friborg O, Barlaug D, Martinussen M, Rosenvinge JH, Hjemdal O. Resilience in relation to personality and intelligence. Int $J$ Methods Psychiatr Res. 2005;14(1):29-42.

58. Friborg O, Hjemdal O. Resilience as a measure of adaptive capacity. Journal of the Norwegian Psychological Association. 2004;41:206-208.

59. Windle G, Bennett KM, Noyes J. A methodological review of resilience measurement scales. Health Qual Life Outcomes. 2011;9(1):8.

60. Scoloveno R. A theoretical model of health-related outcomes of resilience in middle adolescents. Western Journal of Nursing Research. 2014

61. Tambs K, Moum T. How well can a few questionnaire items indicate anxiety and depression? Acta Psychiatr Scand. 1993;87(5):364-367.

62. Lau RS, Cheung GW. Estimating and comparing specific mediation effects in complex latent variable models. Organ Res Methods. 2012;15(1):3-16.

63. Harrell FE. Regression Modeling Strategies: with Applications to Linear Models, Logistic and Ordinal... Regression, and Survival Analysis. 2nd ed. Cham: Springer; 2015.

64. Hayes AF. The simple mediation model. In: Introduction to Mediation, Moderation, and Conditional Process Analysis: a Regression-Based Approach. New York, NY: The Guilford Press; 2013:85-122. 
65. Hu Li-tze, Bentler PM. Cutoff criteria for fit indexes in covariance structure analysis: Conventional criteria versus new alternatives. Structural Equation Modeling: A Multidisciplinary Journal. 1999;6(1):1-55.

66. Muthén LK, Muthén BO. Mplus User's Guide. 7th ed. Los Angeles, CA: Muthén \& Muthén; 1998-2013.

67. Connell AM, Goodman SH. The association between psychopathology in fathers versus mothers and children's internalizing and externalizing behavior problems: a meta-analysis. Psychol Bull. 2002;128(5):746-773.

68. Weijers D, van Steensel FJA, Bögels SM. Associations between psychopathology in mothers, fathers and their children: a structural modeling approach. J Child Fam Stud. 2018;27(6):1992-2003.

69. Goodman SH, Gotlib IH. Risk for psychopathology in the children of depressed mothers: a developmental model for understanding mechanisms of transmission. Psychol Rev. 1999;106(3):458-490.

70. Kahn RS, Brandt D, Whitaker RC. Combined effect of mothers' and fathers' mental health symptoms on children's behavioral and emotional well-being. Arch Pediatr Adolesc Med. 2004;158(8):721-729.

71. Segrin C, Rynes KN. The mediating role of positive relations with others in associations between depressive symptoms, social skills, and perceived stress. J Res Pers. 2009;43(6):962-971.

72. Hudziak JJ, Copeland W, Rudiger LP, Achenbach TM, Heath AC, Todd RD. Genetic influences on childhood competencies: a twin study. J Am Acad Child Adolesc Psychiatry. 2003;42(3):357-363.

73. Bandura A. Self-efficacy: toward a unifying theory of behavioral change. Psychol Rev. 1977;84(2):191-215.

74. Evans S, Shipton EA, Keenan T. The relationship between maternal chronic pain and child adjustment: the role of parenting as a mediator. J Pain. 2006;7(4):236-243.

75. Cree VE. Worries and problems of young carers: issues for mental health. Child \& Family Social Work. 2003;8(4):301-309.

76. Jacobson S, Wood FG. Contributions of children to the care of adults with diabetes. Diabetes Educ. 2004;30(5):820-826.

77. Rose AJ, Rudolph KD. A review of sex differences in peer relationship processes: potential trade-offs for the emotional and behavioral development of girls and boys. Psychol Bull. 2006;132(1):98-131.

78. Nilsen W, Karevold E, Røysamb E, Gustavson K, Mathiesen KS. Social skills and depressive symptoms across adolescence: social support as a mediator in girls versus boys. J Adolesc. 2013;36(1):11-20.
79. Sieh DS, Dikkers AL, Visser-Meily JM, Meijer AM. Stress in Adolescents with a Chronically Ill Parent: Inspiration from Rolland's Family Systems-Illness Model. J Dev Phys Disabil. 2012;24(6):591-606.

80. Steinberg L, Morris AS. Adolescent development. Annu Rev Psychol. 2001;52:83-110.

81. Rubin KH, Bukowski WM, Parker JG. Peer interactions, relationships, and groups. In: Damon W, Lerner RM. Editors. Handbook of Child Psychology. Hoboken, NJ: John Wiley \& Sons, Inc; 2006:571-645.

82. Evans S, de Souza L. Dealing with chronic pain: giving voice to the experiences of mothers with chronic pain and their children. Qual Health Res. 2008;18(4):489-500.

83. Nilsen W, Karevold EB, Kaasbøll J, Kjeldsen A. Nuancing the role of social skills- a longitudinal study of early maternal psychological distress and adolescent depressive symptoms. BMC Pediatr. 2018;18(1):133.

84. Gundersen KK. Social Emotional Competence-too much or too little. The International Journal of Emotional Education. 2014;6(1):4-13.

85. Durlak JA, Wells AM. Primary prevention mental health programs for children and adolescents: a meta-analytic review. Am J Community Psychol. 1997;25(2):115-152.

86. das JK, Salam RA, Lassi ZS, et al. Interventions for adolescent mental health: an overview of systematic reviews. J Adolesc Health. 2016;59(4S):S49-S60.

87. Kline RB. Assumptions in structural equation modeling. In: Hoyle RH, editor. Handbook of Structural Equation Modeling. New York: The Gilford Press; 2012:111-125.

88. Maxwell SE, Cole DA. Bias in cross-sectional analyses of longitudinal mediation. Psychol Methods. 2007;12(1):23-44.

89. Maxwell SE, Cole DA, Mitchell MA. Bias in cross-sectional analyses of longitudinal mediation: partial and complete mediation under an autoregressive model. Multivariate Behav Res. 2011;46(5):816-841.

90. Ranøyen I. Associations between internalizing problems in adolescent daughters versus sons and mental health problems in mothers versus fathers (The HUNT Study). Journal of Child and Family Studies. 2014:1-13.

91. Steingrímsdóttir ÓA, Landmark T, Macfarlane GJ, Nielsen CS. Defining chronic pain in epidemiological studies: a systematic review and meta-analysis. Pain. 2017;158(11):2092-2107.

92. Hayes AF, Baron B. Beyond baron and kenny: statistical mediation analysis in the new millennium. Commun Monogr. 2009;76(4):408-420.

93. Roy R. Chronic Pain and Family: a Clinical Perspective. New York: Springer; 2006. 


\section{Supplementary materials}

Table SI Measurement model presented with standardized factor loadings and standard errors

\begin{tabular}{|c|c|c|c|c|}
\hline & \multicolumn{2}{|l|}{ Girls } & \multicolumn{2}{|l|}{ Boys } \\
\hline & $\boldsymbol{\beta}$ & S.E. & $\beta$ & S.E. \\
\hline \multicolumn{5}{|l|}{ Adolescent observed variables ${ }^{a}$} \\
\hline Anxiety/depression $\rightarrow$ Afraid/anxious & 0.747 & 0.020 & 0.761 & 0.019 \\
\hline Anxiety/depression $\rightarrow$ Tense/uneasy & 0.768 & 0.017 & 0.688 & 0.018 \\
\hline Anxiety/depression $\rightarrow$ Hopelessness & 0.748 & 0.018 & 0.714 & 0.017 \\
\hline Anxiety/depression $\rightarrow$ Dejected/sad & 0.788 & 0.015 & 0.825 & 0.017 \\
\hline Anxiety/depression $\rightarrow$ Worry too much & 0.807 & 0.014 & 0.826 & 0.017 \\
\hline Social competence $\rightarrow$ Make others comfortable & 0.771 & 0.013 & 0.739 & 0.014 \\
\hline Social competence $\rightarrow$ Make friends & 0.852 & 0.011 & 0.831 & 0.011 \\
\hline Social competence $\rightarrow$ Talk to new people & 0.819 & 0.011 & 0.783 & 0.012 \\
\hline Social competence $\rightarrow$ Talk easily & 0.703 & 0.014 & 0.723 & 0.014 \\
\hline \multicolumn{5}{|l|}{ Parental observed variables ${ }^{b}$} \\
\hline Mental distress $(M) \rightarrow$ Calm & 0.917 & 0.008 & 0.904 & 0.008 \\
\hline Mental distress $(\mathrm{M}) \rightarrow$ Happy/optimistic & -0.899 & 0.008 & -0.879 & 0.008 \\
\hline Mental distress $(M) \rightarrow$ Nervous/uneasy & 0.791 & 0.013 & 0.748 & 0.015 \\
\hline Mental distress $(\mathrm{M}) \rightarrow$ Anxious & 0.847 & 0.016 & 0.770 & 0.018 \\
\hline Mental distress $(M) \rightarrow$ Irritable & 0.581 & 0.019 & 0.531 & 0.018 \\
\hline Mental distress $(M) \rightarrow$ Down/depressed & 0.839 & 0.012 & 0.817 & 0.012 \\
\hline Mental distress $(\mathrm{M}) \rightarrow$ Lonely & 0.770 & 0.018 & 0.718 & 0.019 \\
\hline Mental distress $(\mathrm{F}) \rightarrow$ Calm & 0.892 & 0.008 & 0.859 & 0.008 \\
\hline Mental distress $(F) \rightarrow$ Happy/optimistic & -0.866 & 0.009 & -0.820 & 0.008 \\
\hline Mental distress $(\mathrm{F}) \rightarrow$ Nervous/uneasy & 0.779 & 0.013 & 0.788 & 0.013 \\
\hline Mental distress $(F) \rightarrow$ Anxious & 0.793 & 0.017 & 0.799 & 0.014 \\
\hline Mental distress $(\mathrm{F}) \rightarrow$ Irritable & 0.606 & 0.017 & 0.622 & 0.017 \\
\hline Mental distress $(F) \rightarrow$ Down/depressed & 0.826 & 0.013 & 0.828 & 0.012 \\
\hline Mental distress $(\mathrm{F}) \rightarrow$ Lonely & 0.683 & 0.019 & 0.694 & 0.019 \\
\hline
\end{tabular}

Notes: ${ }^{2}$ All loadings were statistically significant $(P<.001) .{ }^{b} M=$ mothers, $F=$ fathers.

\section{Publish your work in this journal}

The Journal of Pain Research is an international, peer reviewed, open access, online journal that welcomes laboratory and clinical findings in the fields of pain research and the prevention and management of pain. Original research, reviews, symposium reports, hypothesis formation and commentaries are all considered for publication.
The manuscript management system is completely online and includes a very quick and fair peer-review system, which is all easy to use. Visit http://www.dovepress.com/testimonials.php to read real quotes from published authors. 